\title{
Concise Total Synthesis of Biologically Interesting Mallotophilippens C and E
}

\author{
Yong Rok Lee, * Xin Li, and Jung Hee Kim \\ School of Chemical Engineering and Technology, Yeungnam University, Gyeongsan 712-749, Korea \\ yrlee@yu.ac.kr \\ Phone: 82-53-810-2529. Fax: 82-53-810-4631
}

\section{Spectral Data}

\section{Table of Contents}

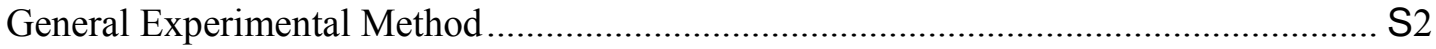

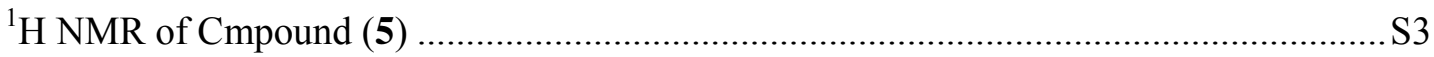

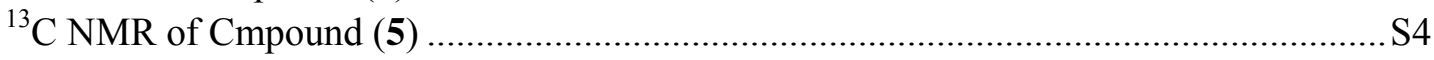

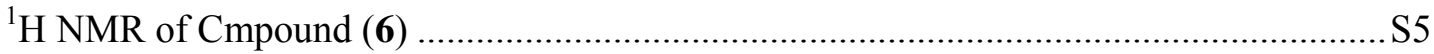

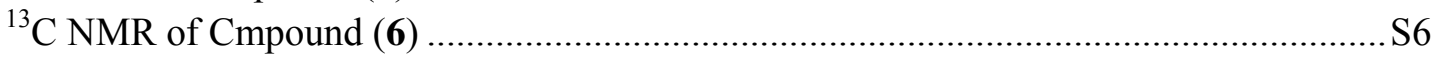

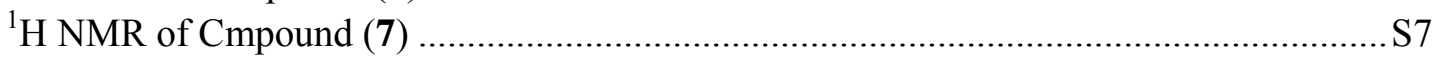

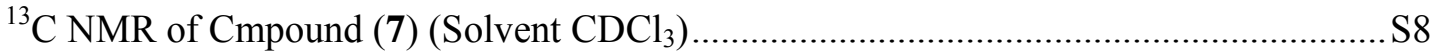

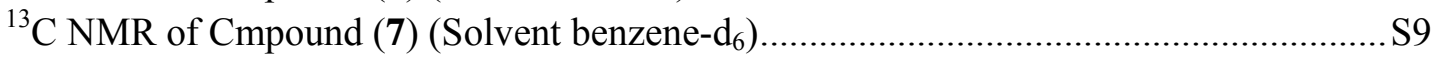

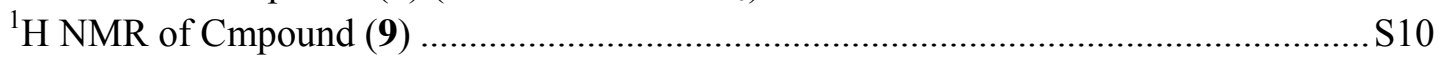

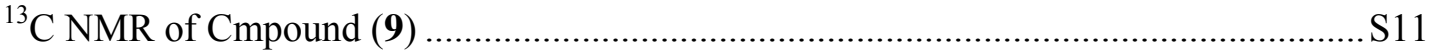

${ }^{1} \mathrm{H}$ NMR of Cmpound Mallotophilippen C (1) ............................................................... 12

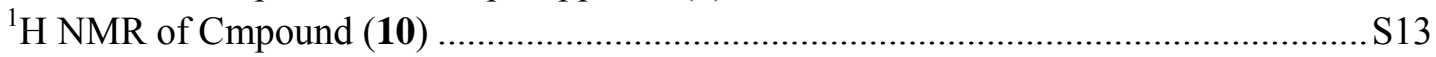

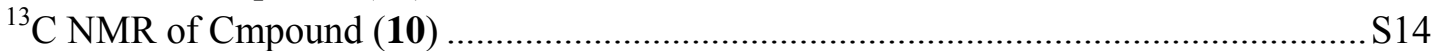

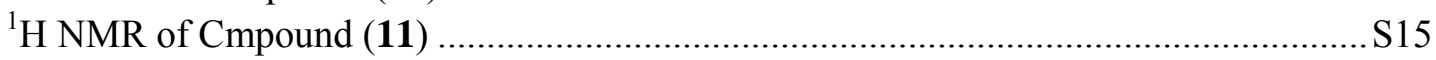

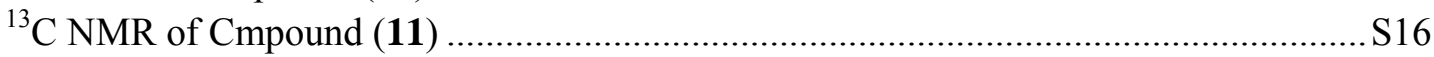

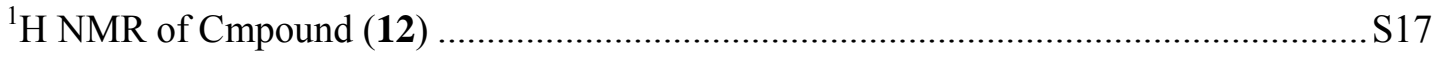

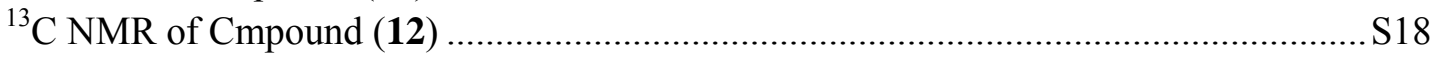

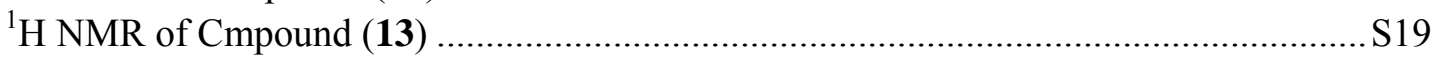

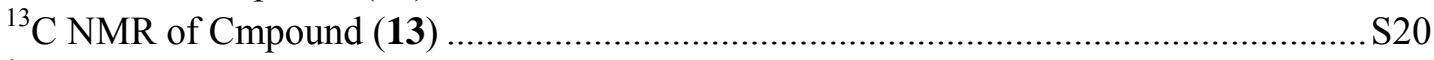

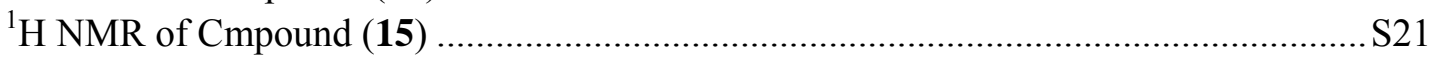

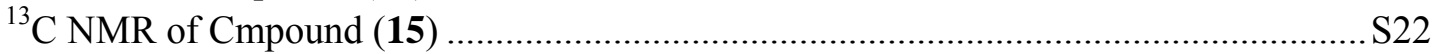

${ }^{1} \mathrm{H}$ NMR of Cmpound Mallotophilippen E (3) ............................................................. S23

${ }^{13} \mathrm{C}$ NMR of Cmpound Mallotophilippen E (3) ............................................................ 24 


\section{General Experimental Method}

All the experiments were carried out in a nitrogen atmosphere. Merck precoated silica gel plates with a fluorescent indicator were used for analytical TLC. Flash column chromatography was performed using silica gel 9385. NMR spectroscopy was carried out in $\mathrm{CDCl}_{3}$ with residual $\mathrm{CHCl}_{3}\left(\delta_{\mathrm{H}}=7.26 \mathrm{ppm}\right)$ and $\mathrm{CDCl}_{3}\left(\delta_{\mathrm{C}}=77.0 \mathrm{ppm}\right)$ as the internal standards, while IR spectra were obtained for thin films on $\mathrm{NaCl}$ plates The HRMS and MS spectra were carried out at the Korea Basic Science Institute. 


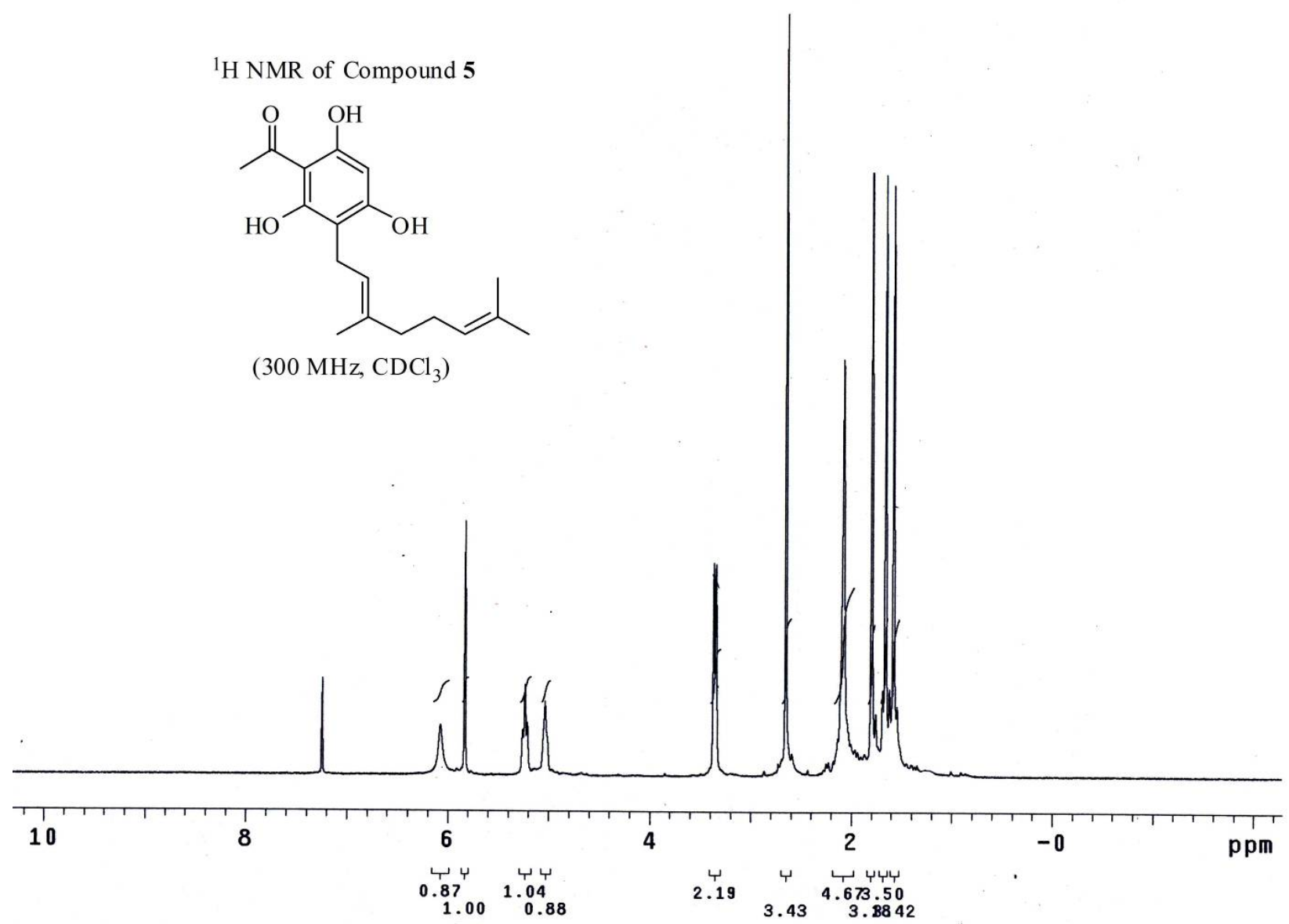


${ }^{13} \mathrm{C}$ NMR of Compound 5

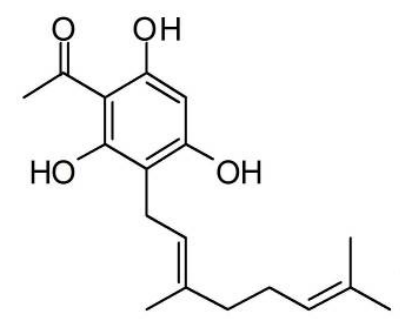

(75 MHz, $\mathrm{CDCl}_{3}$ )

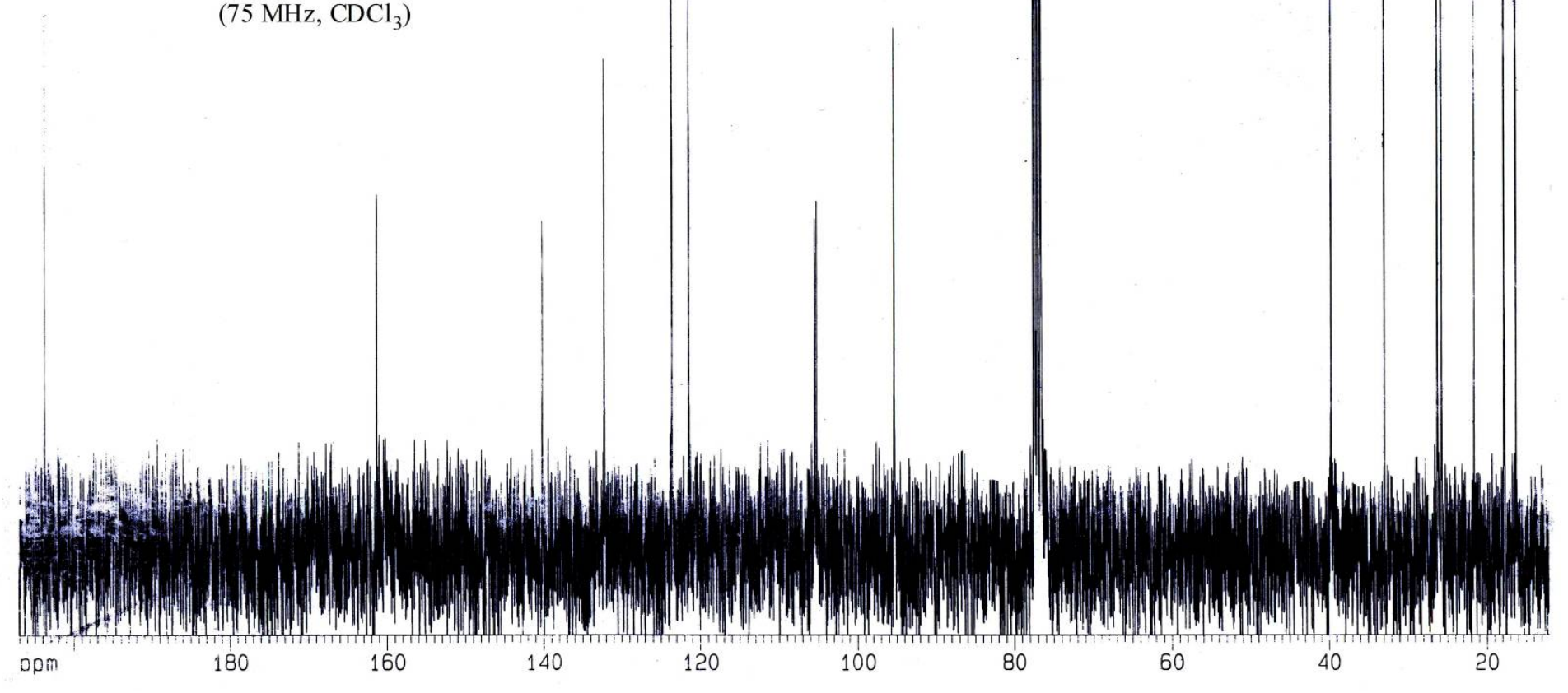


${ }^{1} \mathrm{H}$ NMR of Compound 6

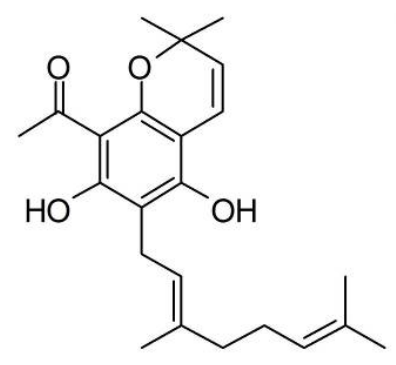

(300 MHz, $\mathrm{CDCl}_{3}$ )

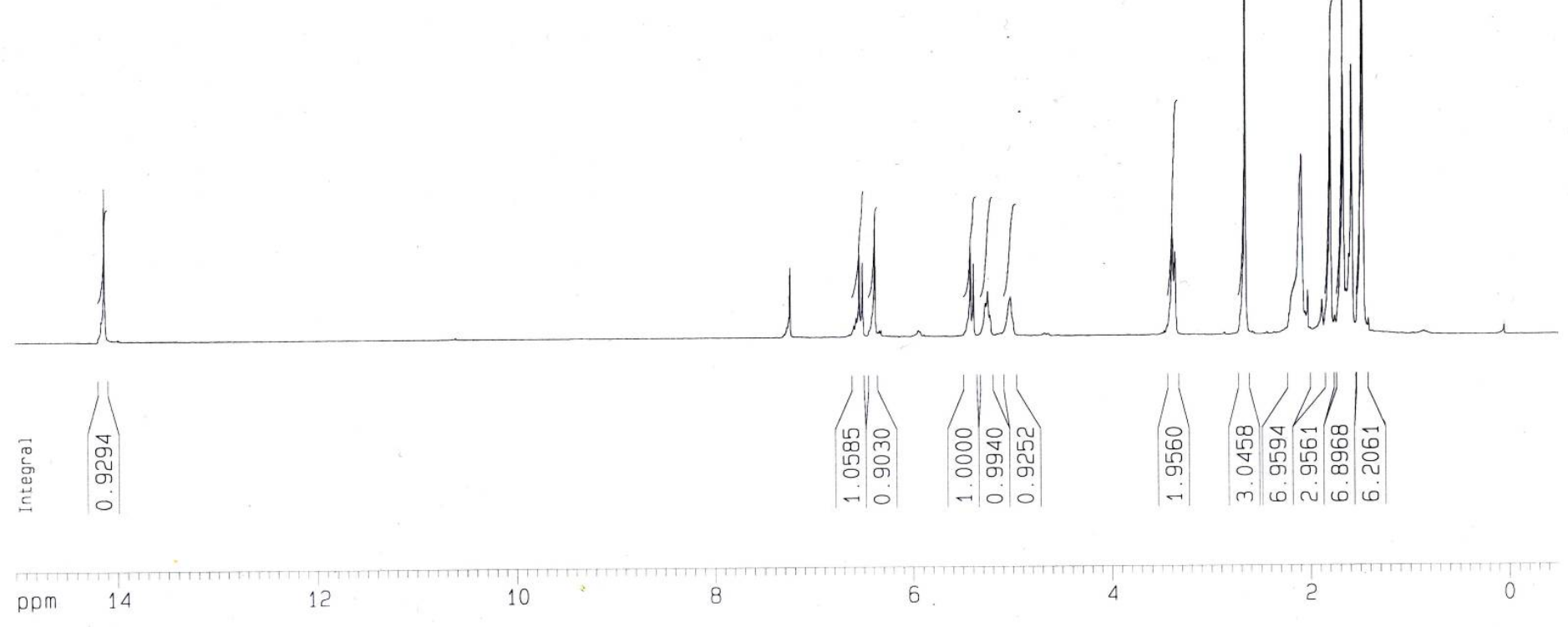


${ }^{13} \mathrm{C}$ NMR of Compound 6

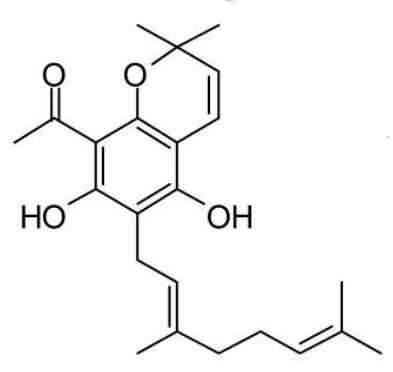

$\left(75 \mathrm{MHz}, \mathrm{CDCl}_{3}\right.$ )

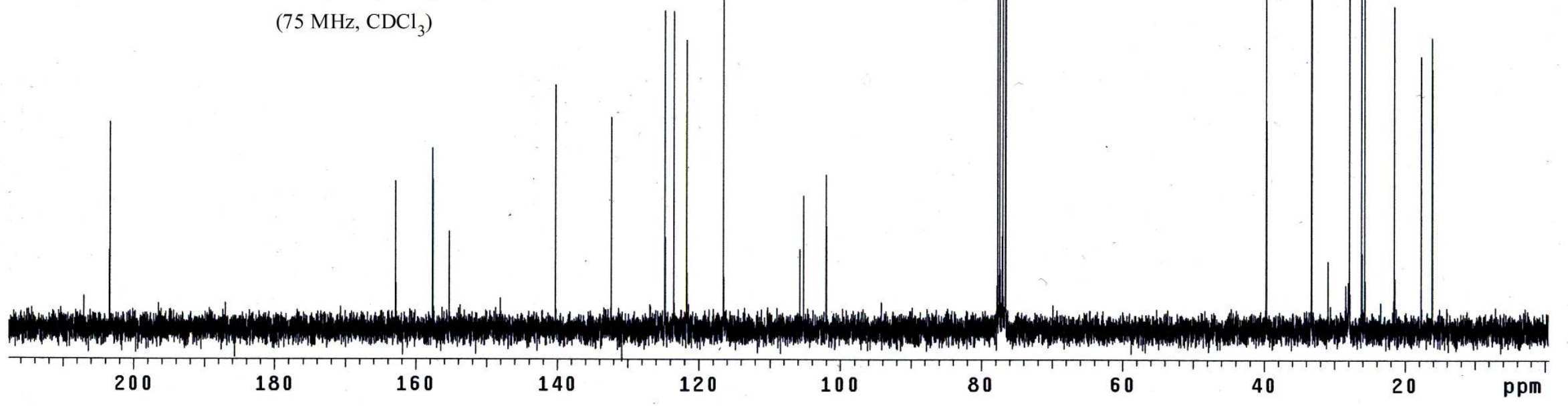



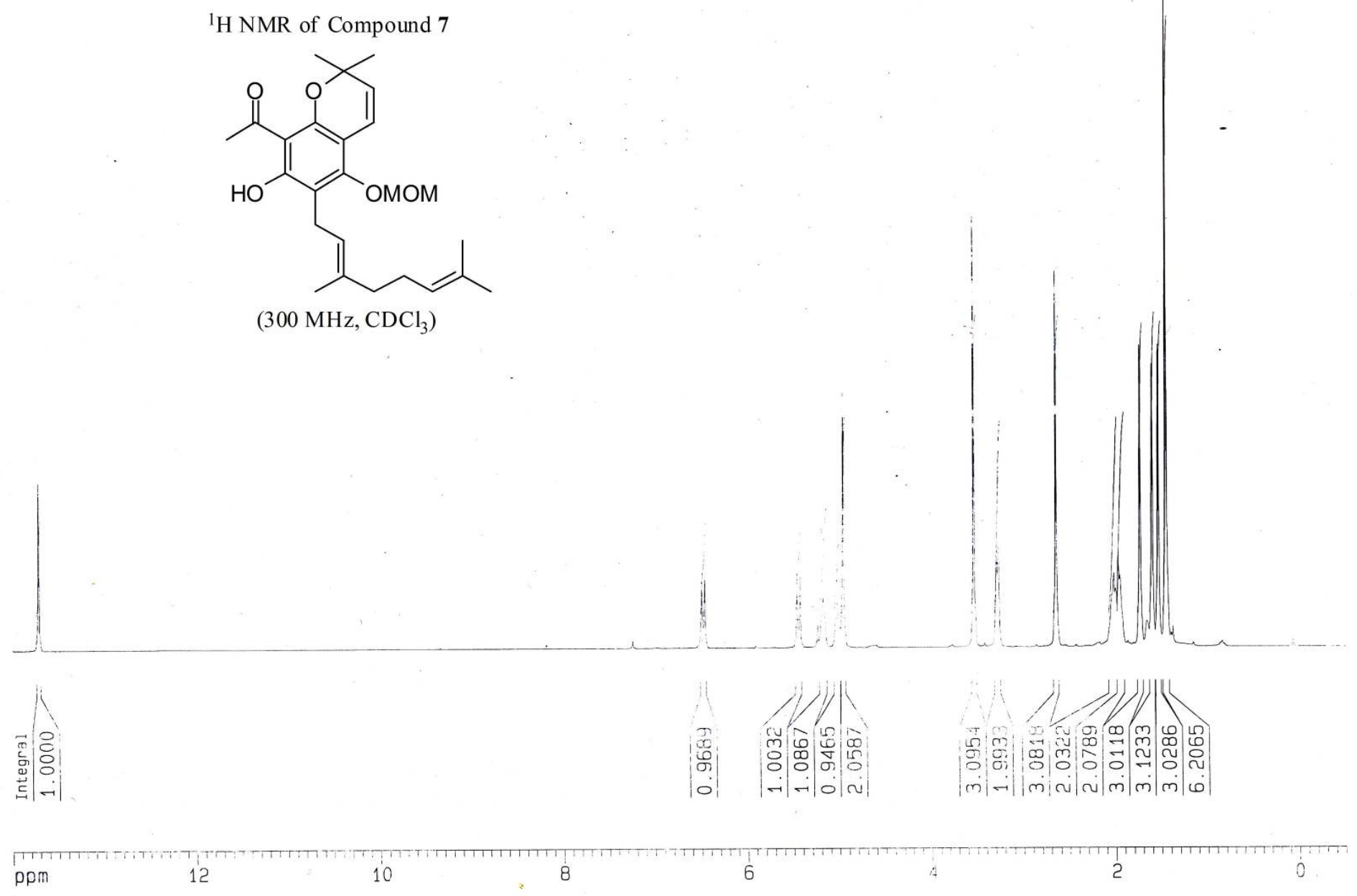


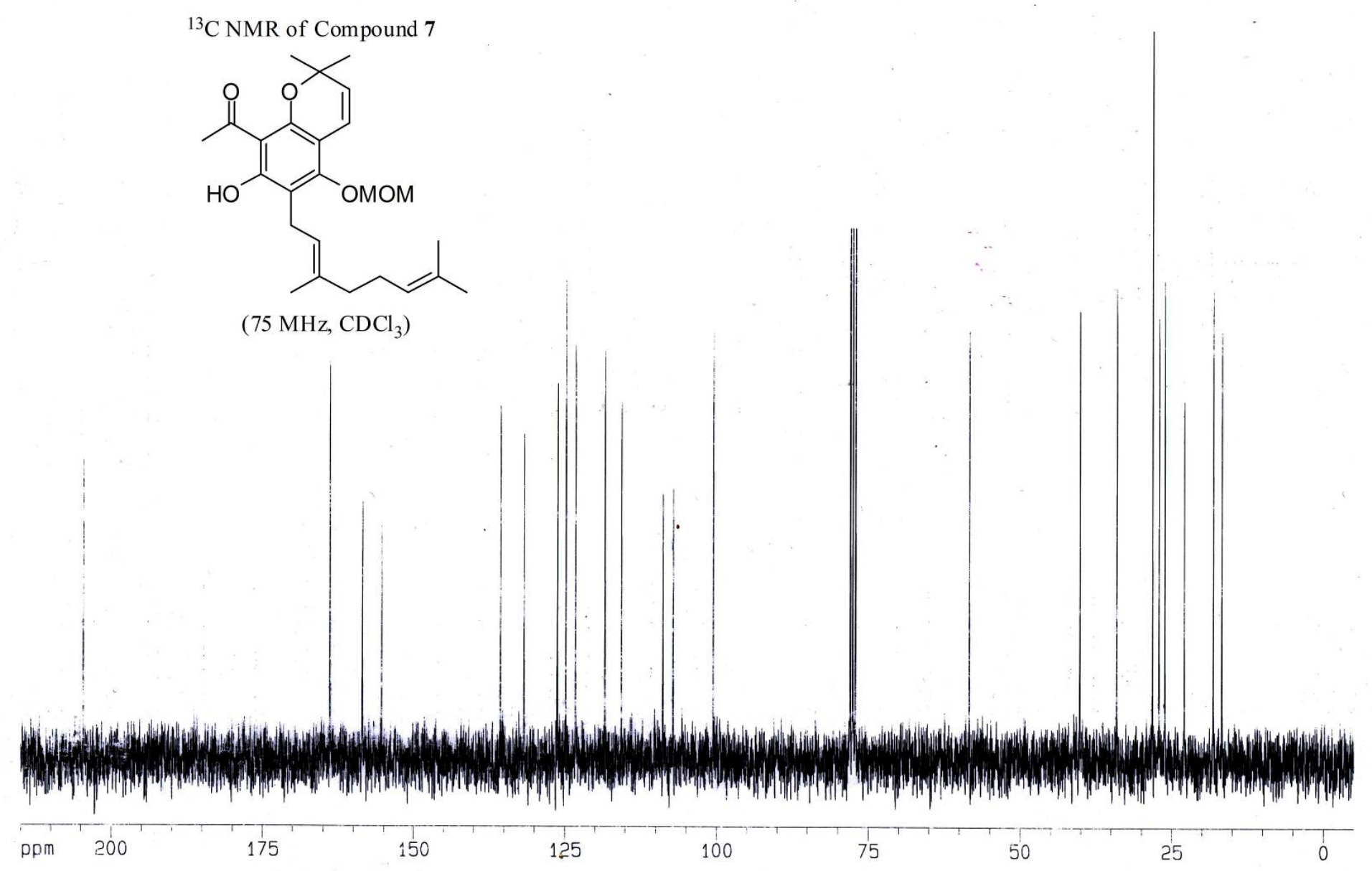




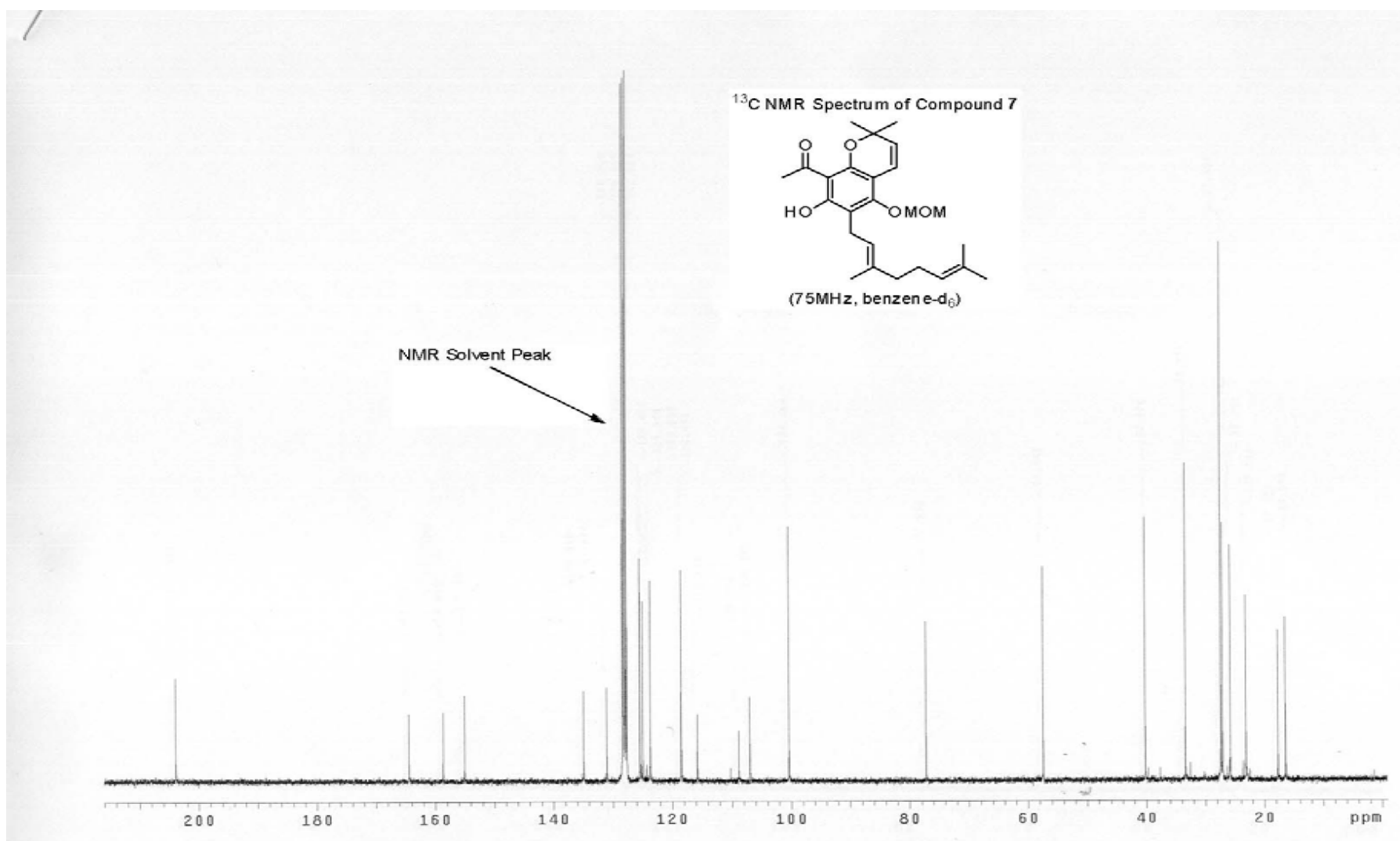

S9 


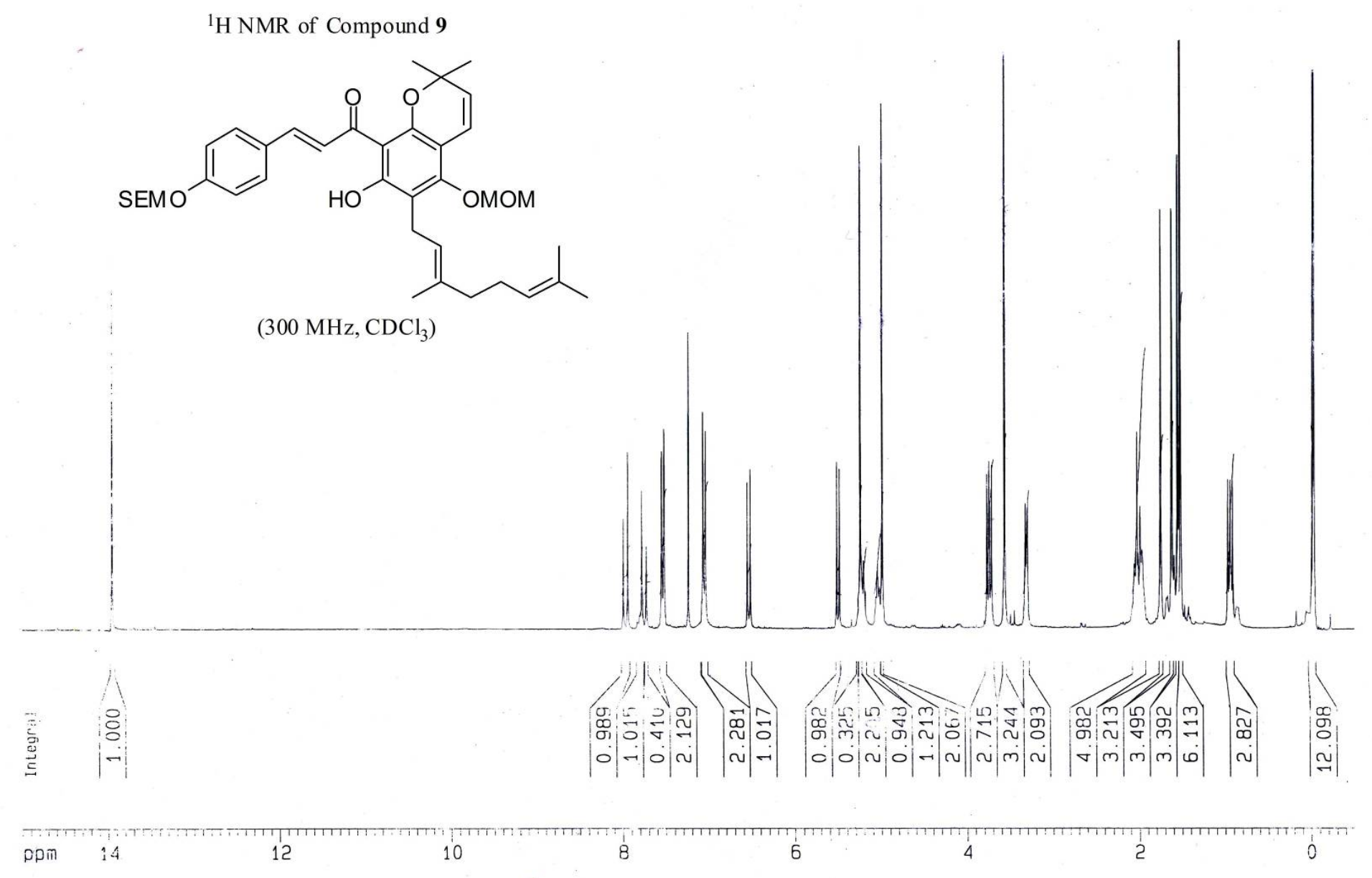




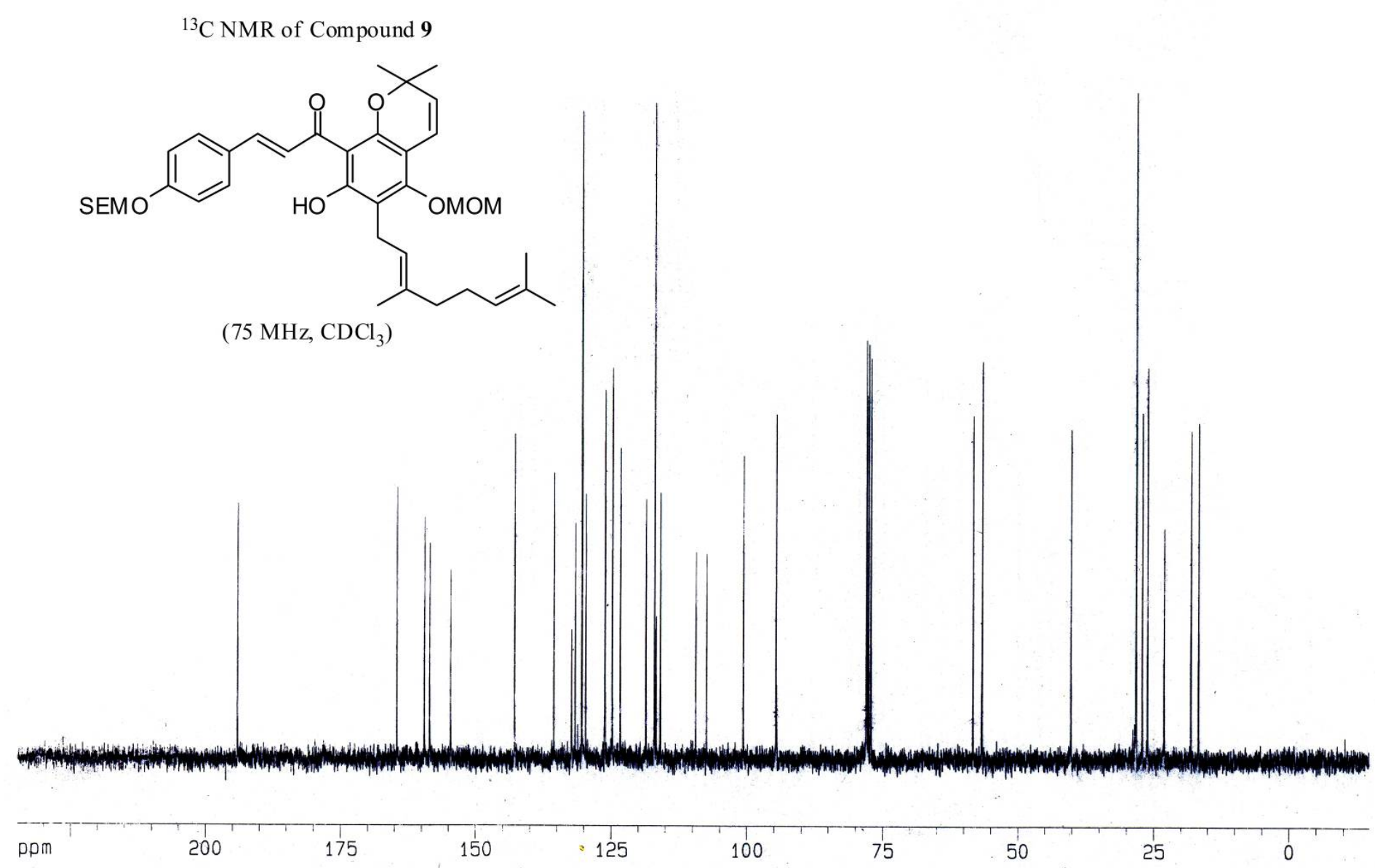



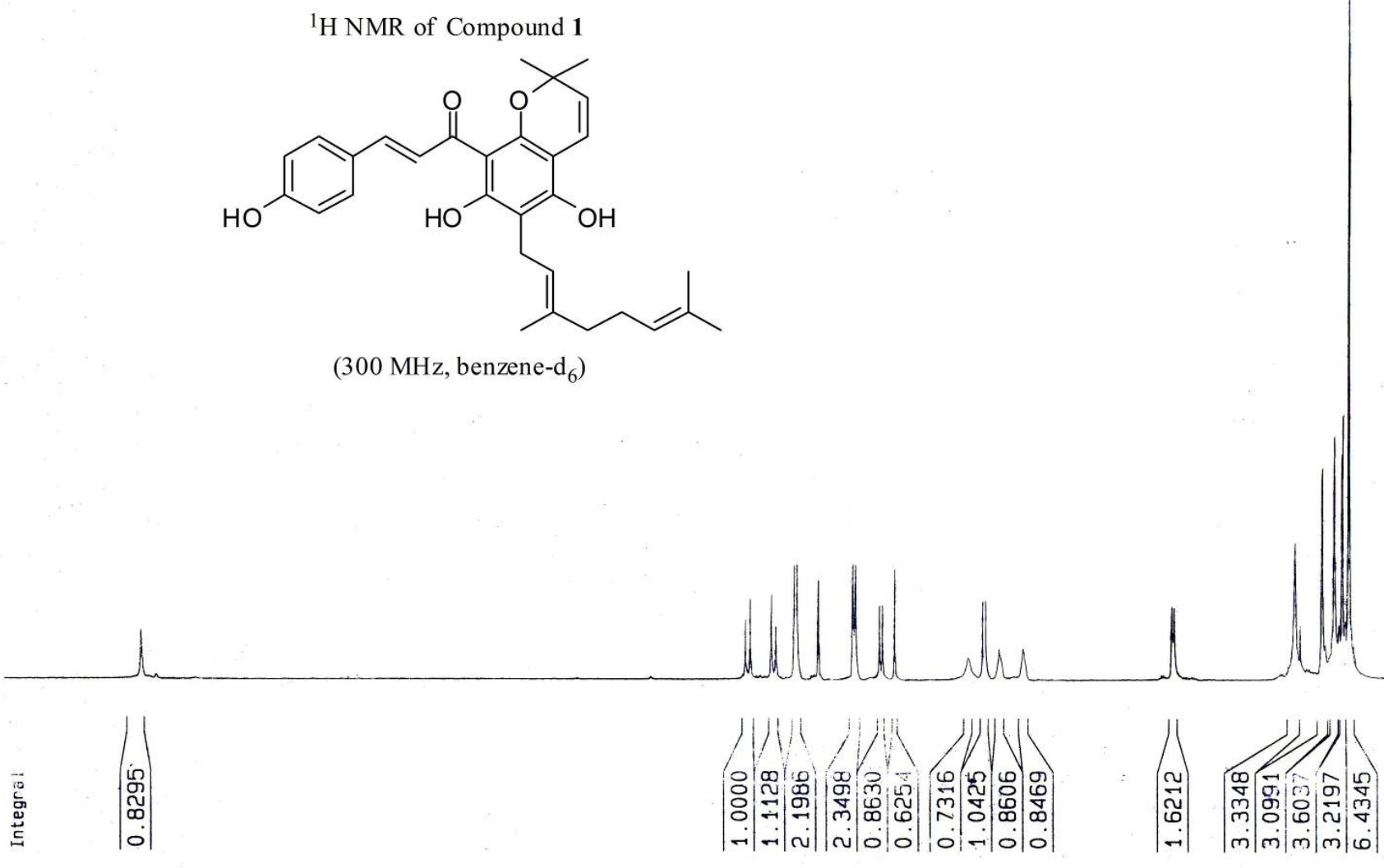

ppm

14

1?

10

8

6

4

2 

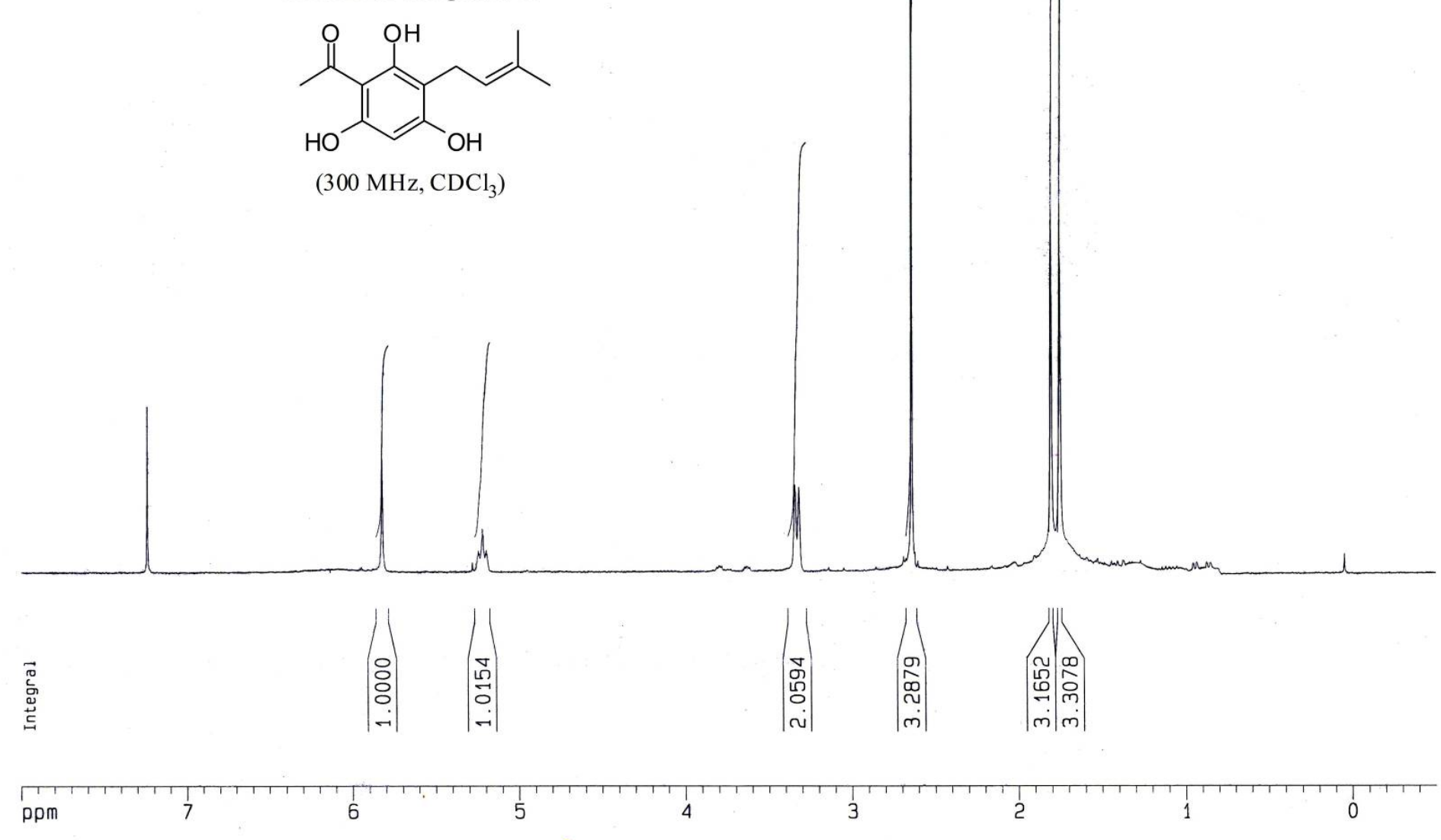


\section{${ }^{13} \mathrm{C}$ NMR of Compound $\mathbf{1 0}$}

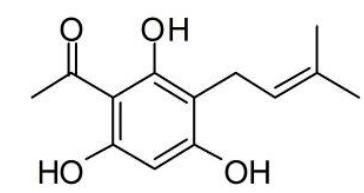

(75 MHz, $\mathrm{CDCl}_{3}$ )

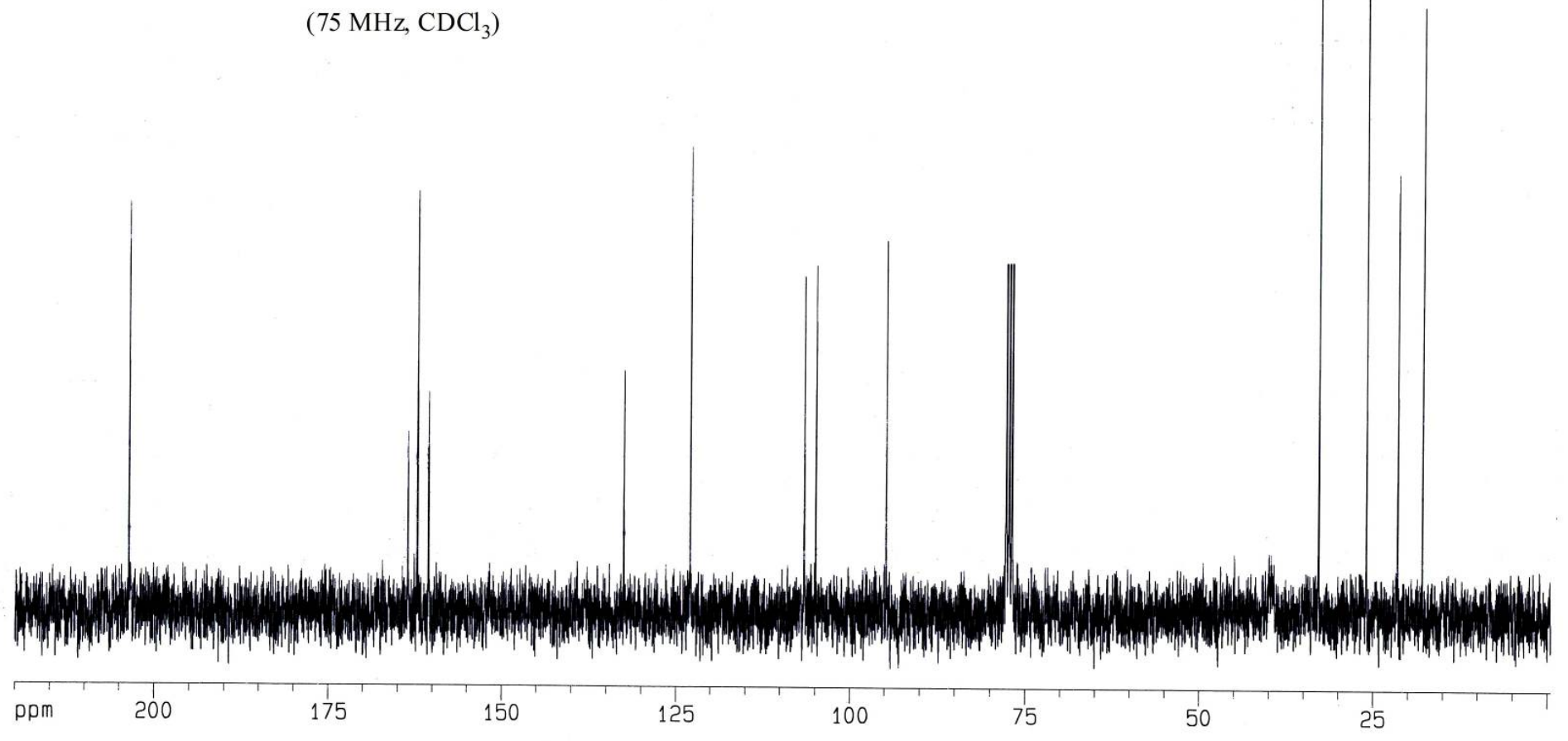




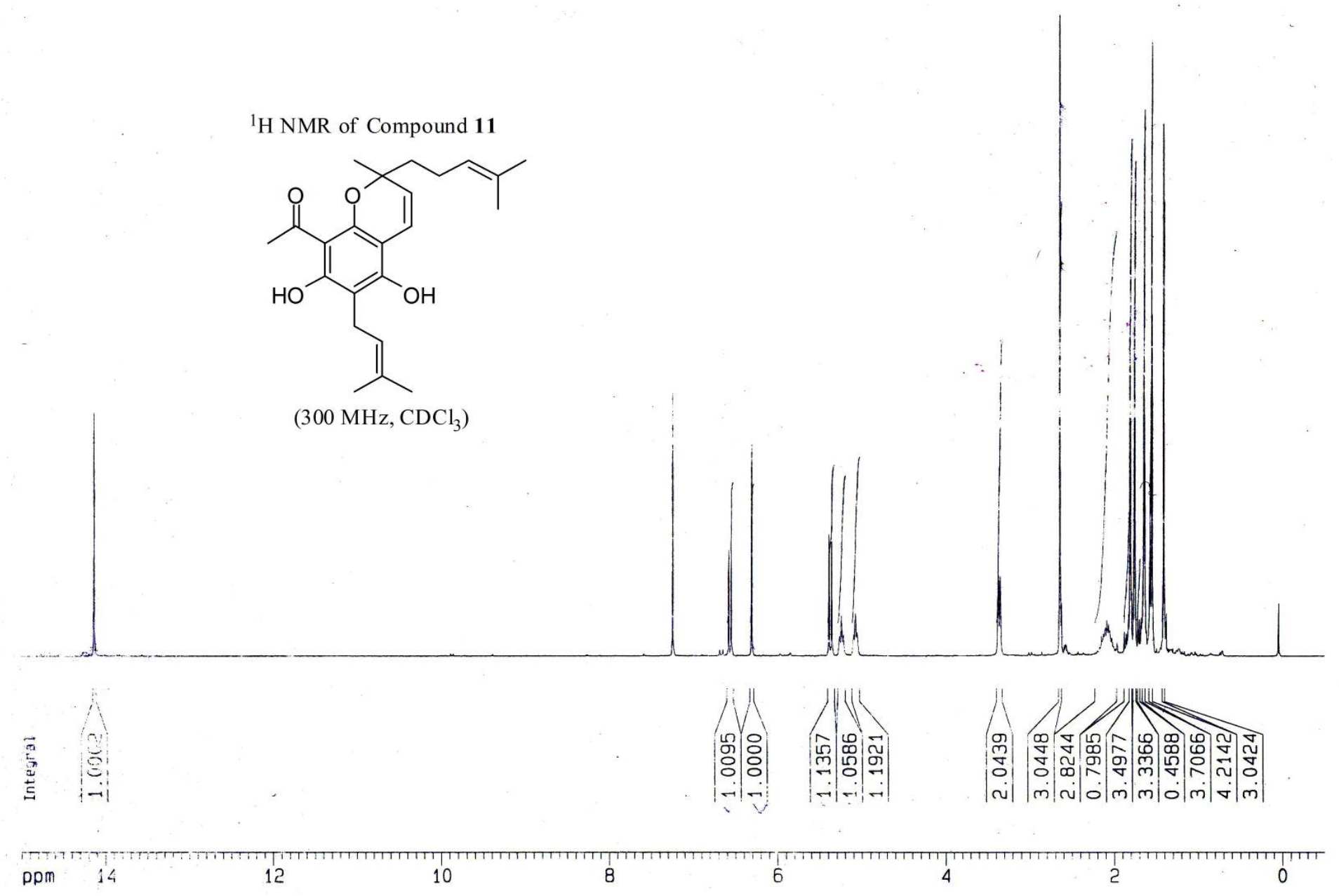


${ }^{13} \mathrm{C}$ NMR of Compound 11

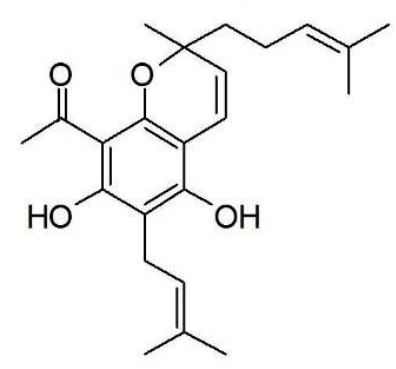

(75 $\mathrm{MHz}, \mathrm{CDCl}_{3}$ )

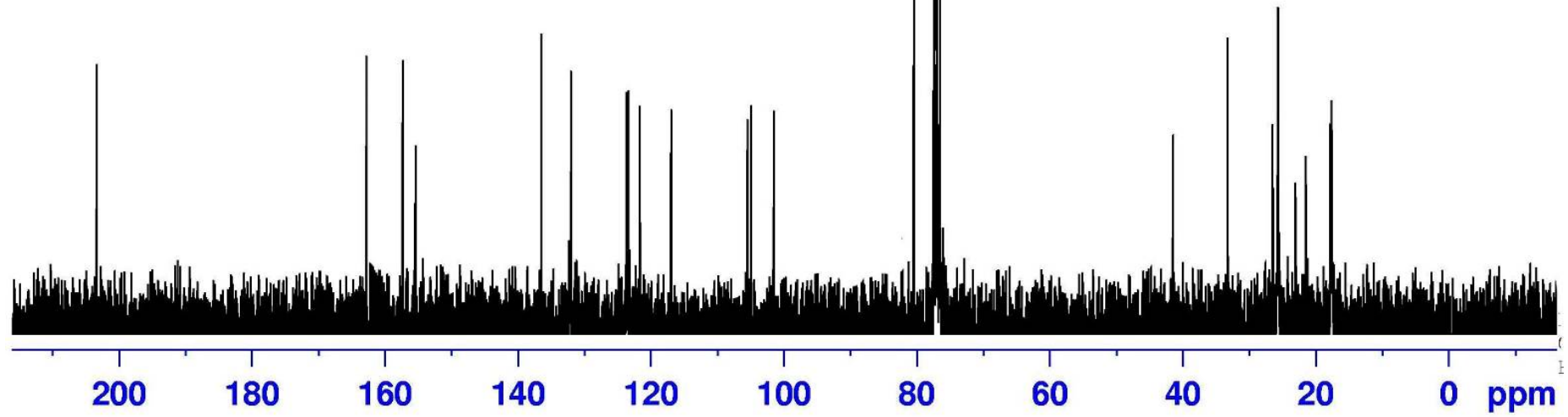




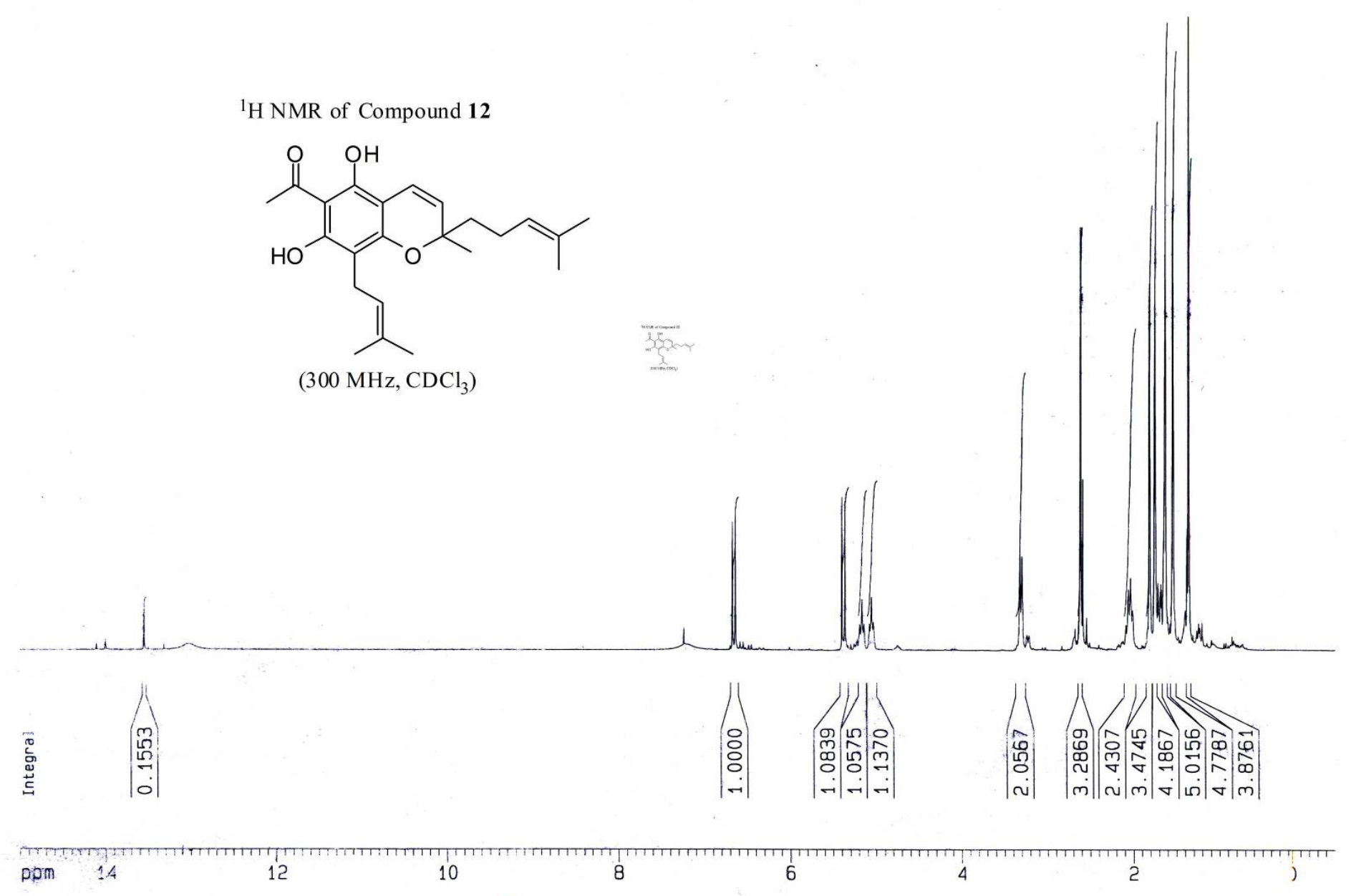




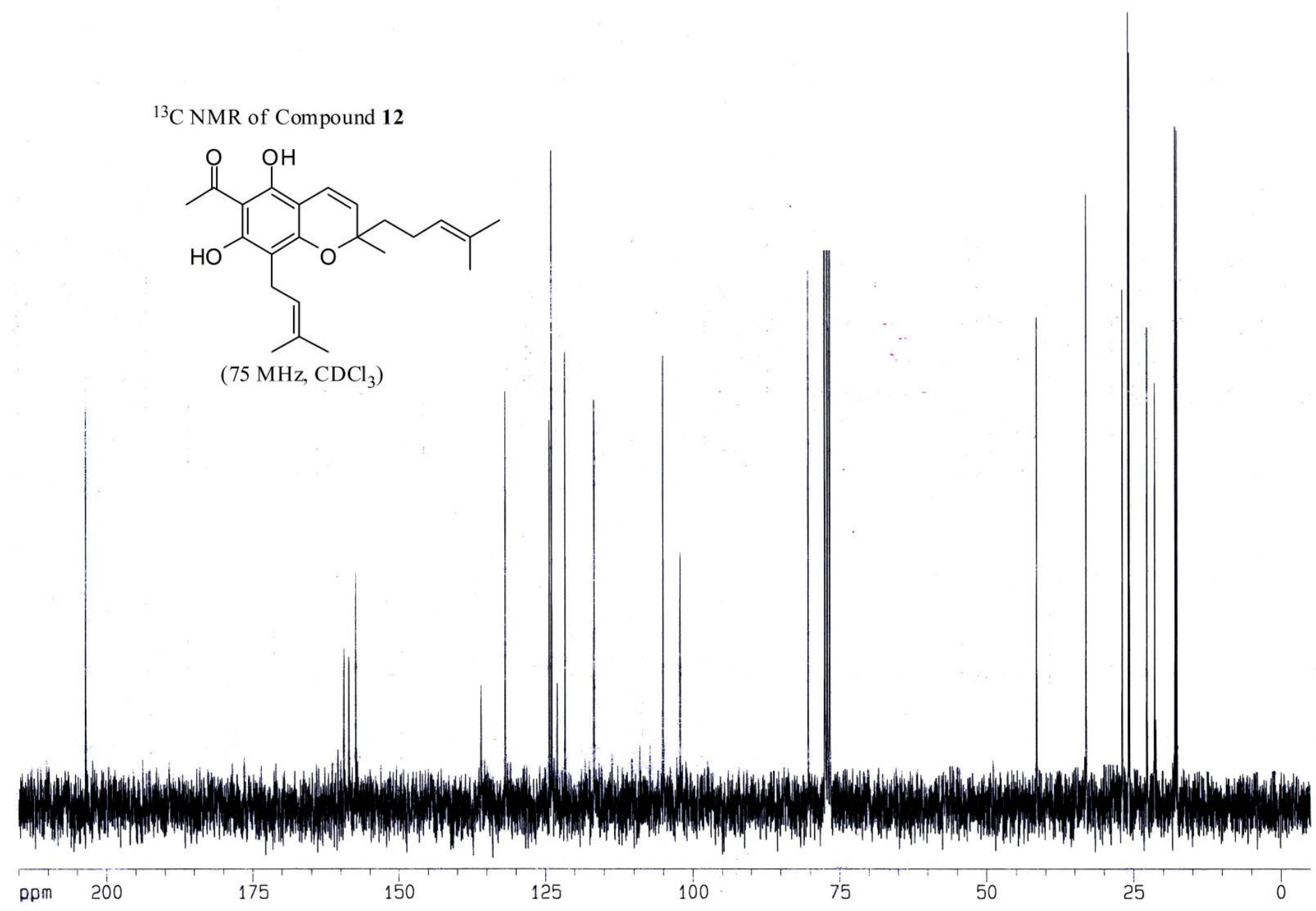




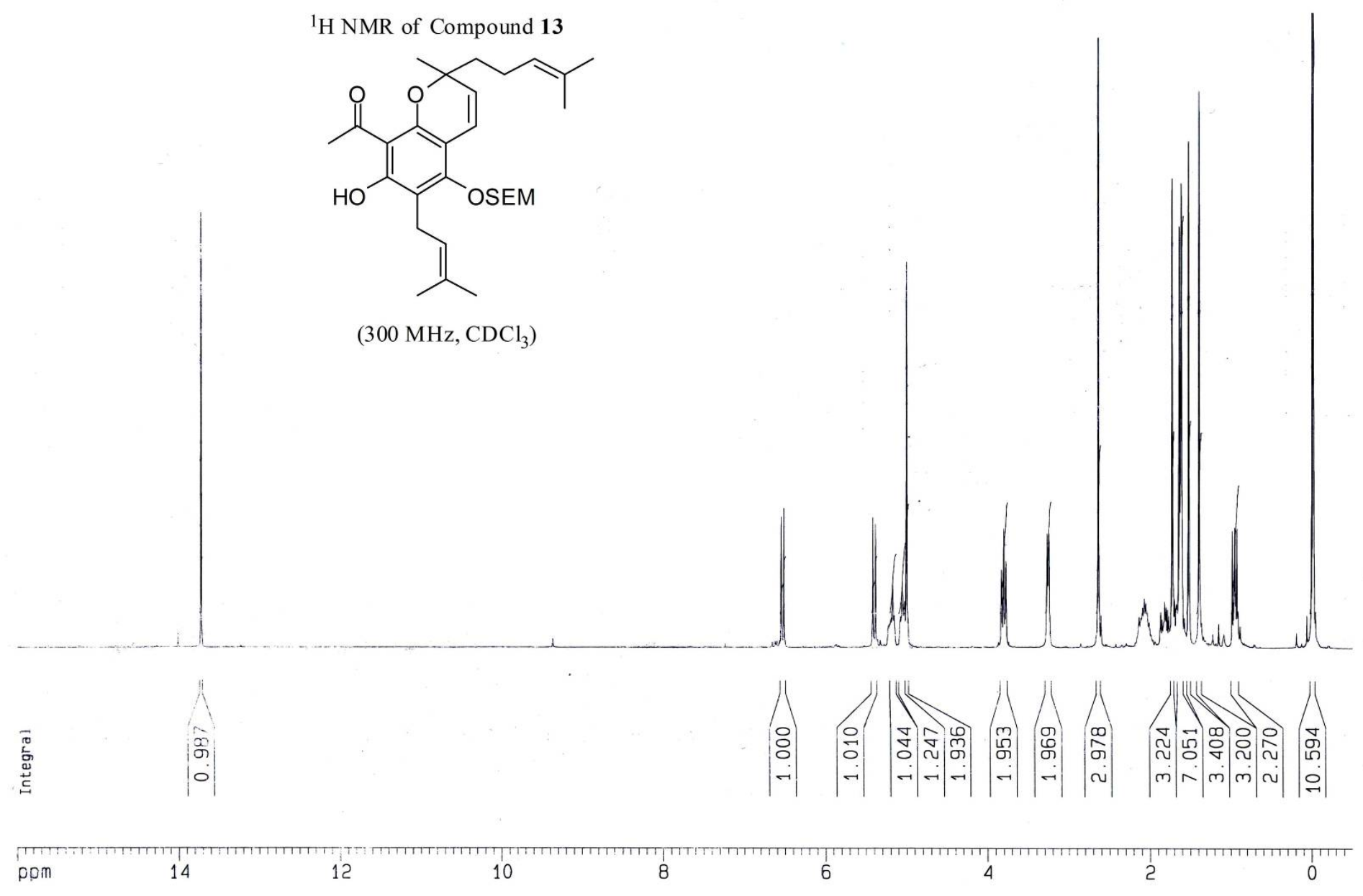


${ }^{13} \mathrm{C}$ NMR of Compound 13

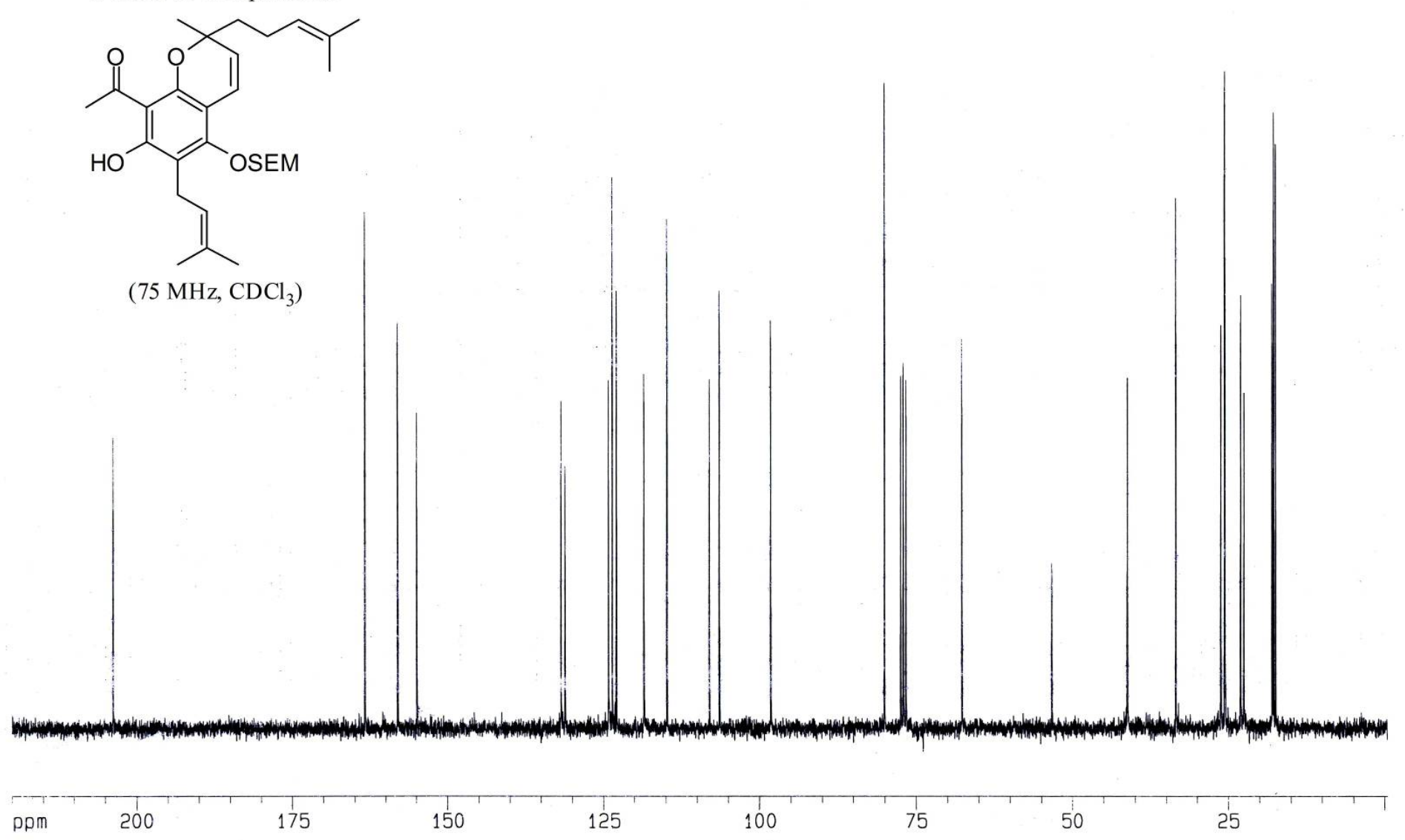




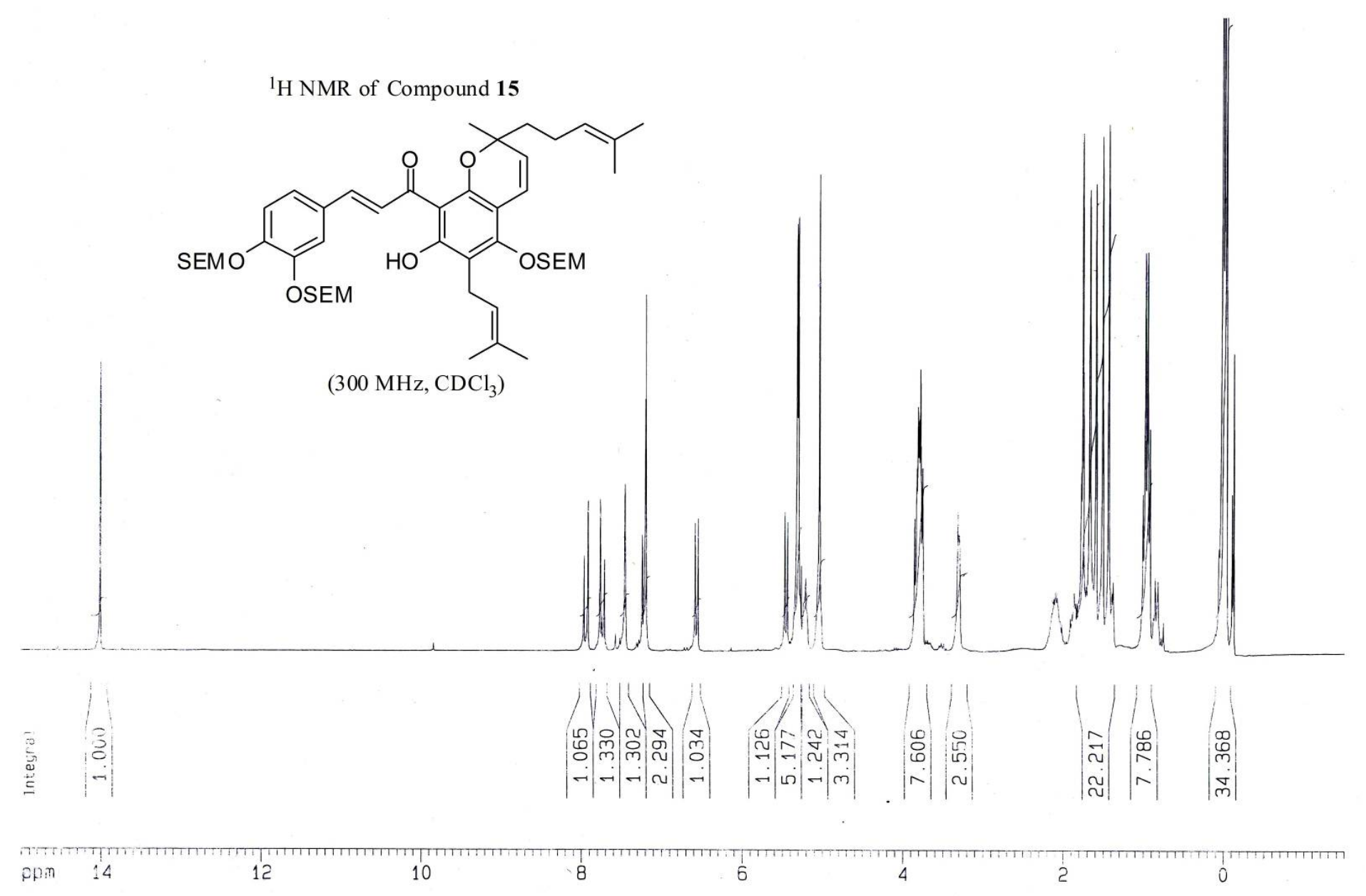




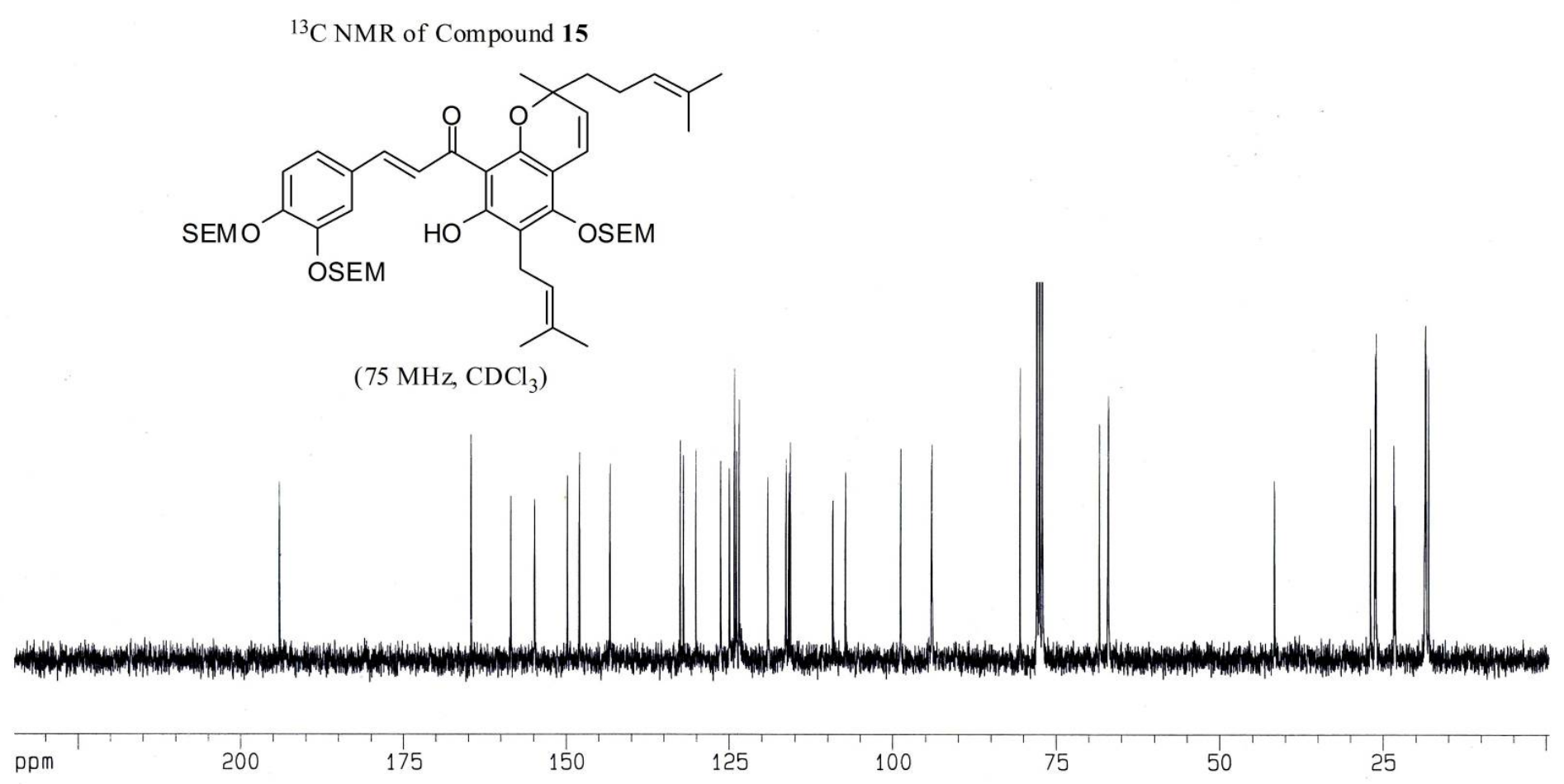




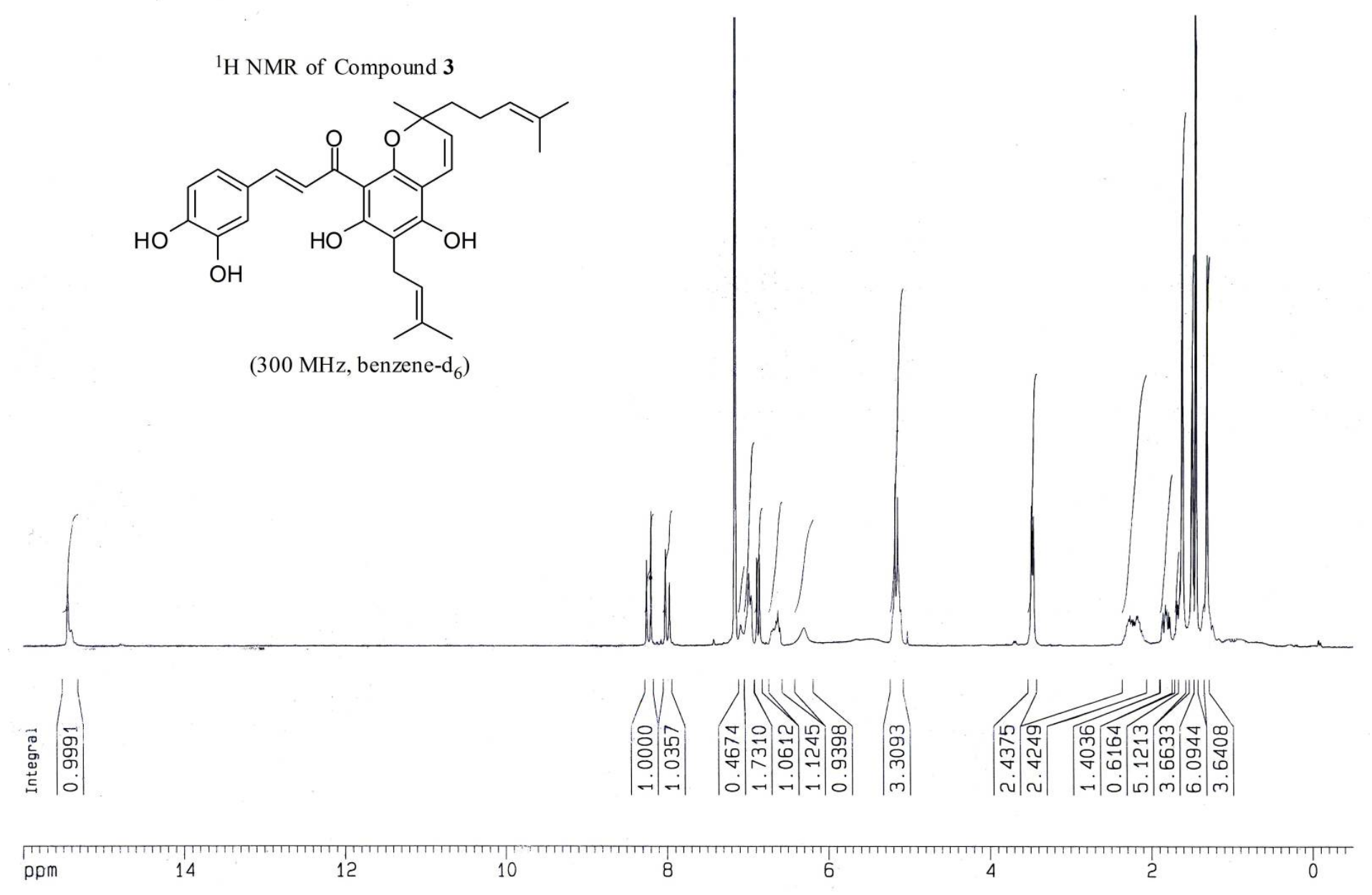




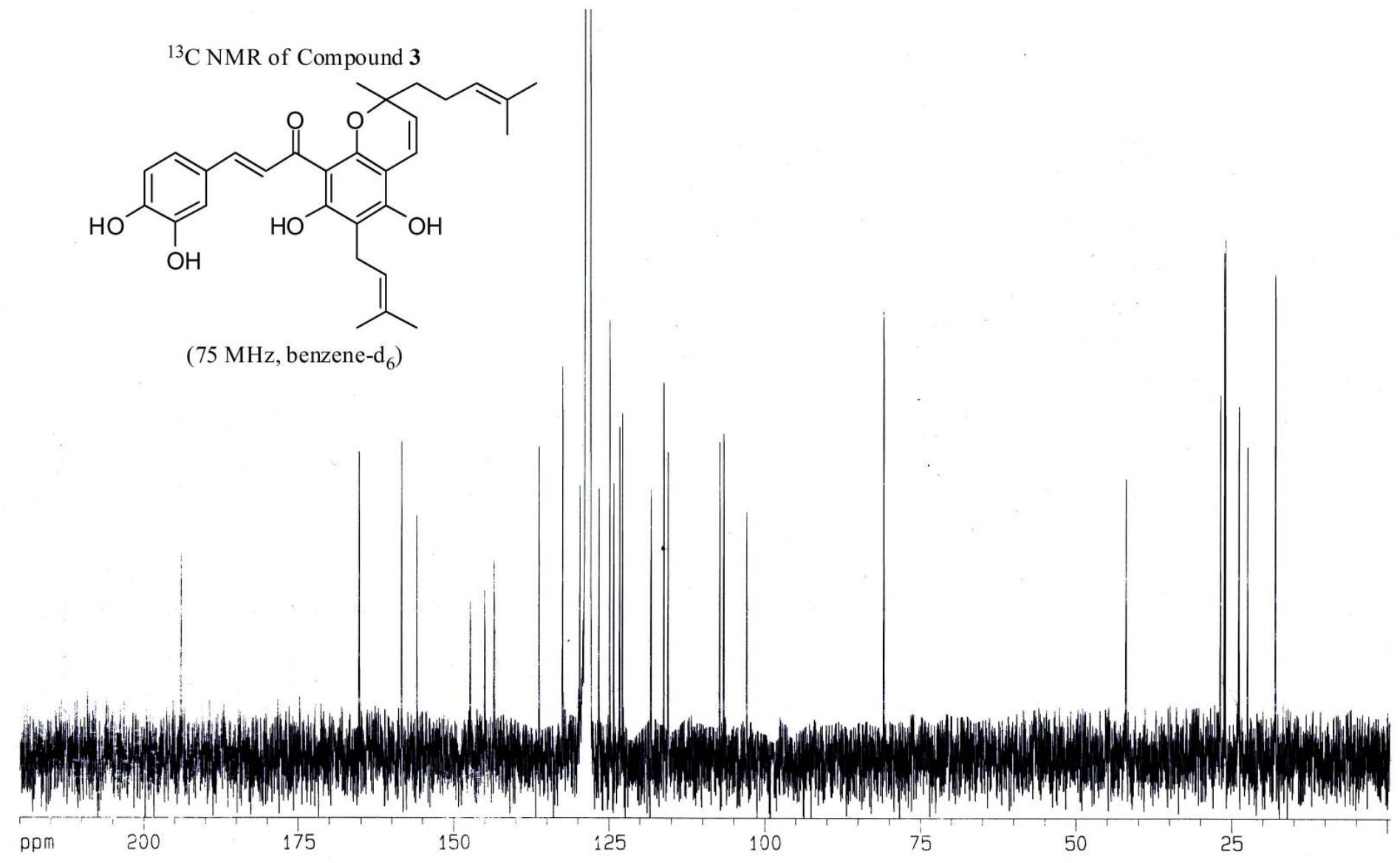

